\title{
PERFIL EMPREENDEDOR: UM ESTUDO DE CASO DO FUNDADOR DA UNOESTE EM PRESIDENTE PRUDENTE
}

Alex de Padua Nogueira 1, Guilherme Luis Torres 2, Marcelo Yassuo de Almeida 3, Raphaela Akemi Hayashida Ambrosio 4, Isabel Cristina Ravazzi Fernandes Nogueira 5

1,2,3 e 4 Discentes do Curso de Administração da UNOESTE. 2 Docente do Curso de Administração da UNOESTE isabelcristina@unoeste.br

\section{RESUMO}

Objetivando destacar o papel do empreendedor como indivíduos que possuem capacidade de inovar e aproveitar oportunidades no mercado e se destacar no mesmo, elaborou-se esse trabalho. 0 desenvolvimento deste artigo baseou-se em pesquisas bibliográficas, sites e também em estudo de caso referente à Universidade do Oeste Paulista (UNOESTE). São apresentadas características do empreendedor e que são usadas para sustentar o estudo de caso. É notável que para alcançar o nível considerável o qual esta universidade alcançou, foi necessário uma liderança empreendedora desde sua fundação. Através de entrevista realizada a um dos fundadores, foi possível notar a presença do empreendedor em todas suas ações frente às diversas situações que foram surgindo até os dias de hoje. Os resultados obtidos com a pesquisa mostram como o indivíduo empreendedor pode alcançar o sucesso profissional e pessoal.

Palavras-chave: Empreendedorismo, Inovação, Planejamento.

\section{ENTREPRENEUR PROFILE: A CASE STUDY OF THE UNOESTE FOUNDER AT PRESIDENTE PRUDENTE}

\begin{abstract}
Aiming to highlight the role of the entrepreneur as individuals who possess ability to innovate and take advantage of market opportunities and stand in the same, has produced this work. The development has been based on bibliographic searches, Web sites, and also in case study for the Unoeste (University of the Western Paulista). The entrepreneur's characteristics are displayed and which are used to support the case study. It is notable that substantial level which was reached, this University necessary entrepreneurial leadership since its founding. Through interview to one of the founders, it was possible to note the presence of the entrepreneur in all its actions against the various situations that arose today. The results of the survey show how enterprising can achieve professional and personal success.
\end{abstract}

Key words: Entrepreneurship, Innovation, Planning. 


\section{INTRODUÇÃO}

O conceito de empreendedorismo é muito subjetivo, todos parecem conhecer, mas não conseguem definir realmente o que seja. Essa subjetividade pode ser devido às diferentes concepções ainda não consolidadas sobre o assunto ou por se tratar de uma novidade, principalmente no Brasil, onde o tema se popularizou a partir da década de 90 . A ascensão do empreendedorismo vem paralelamente ao processo de privatização das grandes estatais e abertura do mercado interno para concorrência externa. Daí a grande importância de desenvolver empreendedores que ajudem o país no seu crescimento e gere possibilidade de trabalho, renda e maiores investimentos.

A atitude de pedir demissão de um bom emprego, com bom salário e abrir o próprio negócio pode parecer algo sem propósito para algumas pessoas. Pois essa é a diferença entre o indivíduo comum e o indivíduo empreendedor. Abrir seu próprio negócio em um país burocrático como o Brasil, pode ser o principal obstáculo para essas pessoas desafiadoras.

Contudo, parece que uma definição de empreendedor que atende na atualidade é de Dornelas (2001, p. 37), que está baseada nas diversas definições vistas até então, "o empreendedor é aquele que detecta uma oportunidade e cria um negócio para capitalizar sobre ela, assumindo riscos calculados". Apesar de o empreendedorismo estar cada vez mais em evidência nos artigos, revista, internet, livros e aparentar ser um termo "novo" para os profissionais, é um conceito antigo que assumiu diversas vertentes ao longo do tempo. Só no início do século $\mathrm{XX}$, a palavra empreendedorismo foi utilizada pelo economista Joseph Schumpeter em 1950 como sendo, de forma resumida, uma pessoa com criatividade e capaz de fazer sucesso com inovações. Mais tarde, em 1967 com K. Knight e em 1970 com Peter Drucker foi introduzido o conceito de risco, uma pessoa empreendedora precisa arriscar em algum negócio, um risco calculável. E em 1985 com Pinchot foi introduzido o conceito de intraempreendedor, uma pessoa empreendedora, mas dentro de uma organização.

Segundo Dornelas (2001), o empreendedorismo ganhou força no Brasil somente a partir da década 1990, com a abertura da economia que propiciou a criação de entidades como SEBRAE (Serviço Brasileiro de Apoio às Micro e Pequenas Empresas) e SOFTEX (Sociedade Brasileira para Exportação de Software). Antes desse momento o termo empreendedor era praticamente desconhecido e a criação de pequenas empresas era limitada, em função do ambiente político e econômico que em nada propiciava ao país.

A entrada de produtos importados ajudou a controlar os preços, uma condição importante para o país voltar a crescer, mas trouxe problemas para alguns setores que não conseguiam competir com os importados, como foi o caso dos setores de brinquedos e de confecções, por exemplo. Para ajustar o passo com o resto do mundo, o País precisou mudar. Empresas de todos os tamanhos e setores tiveram que se modernizar para poder competir e voltar a crescer. O governo deu início a uma série de reformas, controlando a inflação e ajustando a economia, em poucos anos o País ganhou estabilidade, planejamento e respeito. A economia voltou a crescer. Só no ano 2000 , surgiu um milhão de novos postos de trabalho. Investidores de outros países voltaram a aplicar seu dinheiro no Brasil e as exportações aumentaram. E, as micro e pequenas empresas ganharam mais espaço e importância na economia. Hoje, de cada 100 empresas brasileiras, 95 são micro ou pequenas empresas. Juntas elas empregam cerca de 40 milhões de trabalhadores, mais da metade de toda mão-de-obra do País. Os 
números são grandes, mas o espaço para crescimento é ainda maior. O futuro é promissor e cabe, a cada um de nós, fazer dele uma realidade.

Portanto, percebe-se que o início da difusão do empreendedorismo no Brasil, nasce por conveniência do governo e sobrevivência de muitos trabalhadores que saíram das grandes estatais após o processo de privatização.

\section{2- CARACTERISTICAS QUE LEVAM O INDIVIDUO A SE TORNAR UM EMPREENDEDOR}

O empreendedor de um modo geral é caracterizado por ser um indivíduo com muita determinação, que anseia conquistar novos espaços, desenvolve e cria novos produtos e métodos de produção.

De acordo com Pereira e Santos (1995, p.47):

O empreendedor bem sucedido é uma pessoa como qualquer outra, cujas características de personalidade e talentos preenchem um padrão determinado, que o leva a agir de tal forma que chegue ao sucesso, realizando seus sonhos e alcançando seus objetivos.

Segundo Machado (2007), os empreendedores possuem como principais características a inovação, capacidade de criar algo novo, criatividade, necessidade de realização e também a necessidade de iniciar um novo empreendimento. Assim, usam essas características para criar algo novo e que seja útil.

Conforme Rausp (apud ARAUJO, 2010, p.2):

A função do empreendedor é reformar ou revolucionar $o$ padrão de produção pela exploração de uma invenção ou, mais genericamente, uma possibilidade tecnológica ainda não testada para a produção de novas mercadorias ou de algo já existente, mas de uma nova maneira, pelo descobrimento de novas fontes de suprimento de materiais ou nova distribuição para os produtos e pela organização de uma nova indústria.

Devido ao rápido avanço do cenário econômico, o desafio do empreendedor consiste em não somente criar um negócio, mas também o tornar sustentável e disponibilizar além de técnicas e infra-estrutura, maneiras de pensar e agir com inovação.

Segundo Araújo (2010, p.4), as características de um empreendedor são:

- Capacidade de assumir riscos calculados

- Aproveitar as oportunidades

- Buscar informações do ramo empresarial

- Planejar

- Liderança, comprometimento pessoal e otimismo

- Persistência e espírito empreendedor:

- Autoconfiança e independência pessoal

Neste contexto é necessário que se realize uma junção dessas características e as administre da melhor forma para que possa realmente desempenhar 0 papel de empreendedor.

\section{3- O EMPREENDEDOR BEM SUCEDIDO}

O empreendedor de sucesso pode ser considerado como o indivíduo que está sempre a observar negócios na constante procura de oportunidades, portador das condições necessárias para empreender e que busca absorver tudo o que contribui para a criação, desenvolvimento e realização da visão. A criatividade é orientada pela observação de outros negócios, associação de idéias, sucessos e fracassos.

O empreendedor deve ter a capacidade de reconhecer oportunidades, as quais surgem 
principalmente decorrentes das mudanças na tecnologia, políticas, sociais e demográficas.

Aproveitando dessas mudanças, poderá promover a criação de novos produtos e serviços, novos métodos de produção, novos mercados a serem atingidos, novas formas de organização e a utilização de novas matérias-primas.

Segundo Rausp (apud ARAUJO, 2010, p.6):

Os empreendedores não são apenas aqueles que têm idéias, criam novos produtos ou processos. São os que programam, lideram equipes e vendem suas idéias. É difícil encontrar todas essas características em uma única pessoa, por isso, a identificação do perfil de cada uma é fundamental e o trabalho em equipe é fator essencial para o possível sucesso dos empreendedores dentro de uma organização.

Devem não apenas oferecer algo novo, mas também liderar sua equipe e estimular 0 trabalho em conjunto e com objetivos comuns que resultam em resultados muito satisfatórios.

\section{4- EMPREENDEDORISMO NO BRASIL}

Segundo Prosdócimo (2002), estima-se que no Brasil em 2002, 14,4 milhões de pessoas estavam envolvidas com alguma atividade empreendedora, cerca que de cada sete brasileiros, um estava empreendendo. Esses dados colocaram o país em sétimo lugar na classificação mundial em empreendedorismo. $\mathrm{Na}$ contagem global, o Brasil participa com $5 \%$ dos 286 milhões dos empreendedores ativos em 2002 nos 37 países entrevistados. Constate-se então, o povo brasileiro é considerado um dos mais empreendedores do mundo.

Muitos de nossos empreendedores criam negócios por falta de oportunidade de trabalho, sendo chamados de empreendedores por necessidades, mas apesar de esta parcela ser significativa, o brasileiro tem um alto grau de ousadia, aceita assumir riscos e tem a habilidade para criar novas empresas.

De acordo com Prosdócimo (2002, p. 13):

A redução dos investimentos estrangeiros, o encolhimento dos mercados locais, a instabilidade dos parâmetros econômicos, as incertezas no contexto político, limitações na infra-estrutura básica entre outros, testemunhados nos últimos dois anos, mesmo com a manutenção de um certo nível de investimentos em setores mais dinâmicos da economia e da opção pela exportação, têm impacto direto na exploração de novas oportunidades e na própria intenção em assumir riscos de difícil cálculo por parte do empreendedor.

Além das dificuldades encontradas para se qualificar, existem também as dificuldades encontradas no próprio mercado que sofre constantes alterações que muitas vezes não eram previstas.

Para Dornelas (apud BARBOSA; ANDRADE, 2002), os empreendedores brasileiros são considerados heróis por conseguirem ultrapassar todas essas dificuldades e ainda alcançarem seus objetivos. Assim, é possível que se tenha uma base das dificuldades encontradas pelos empreendedores de nosso país e que realmente são vitoriosos quando alcançados seus objetivos.

\section{5- ESTUDO DE CASO: SURGIMENTO DA UNIVERSIDADE DO OESTE PAULISTA - UNOESTE}

A Apec - Associação Prudentina de Educação e Cultura, mantenedora da Unoeste Universidade do Oeste Paulista, nasceu do sonho dos professores Agripino e Ana Maia de Oliveira Lima de suprir a carência de ensino superior em Presidente Prudente e região. 
Em maio de 1972, estes educadores entravam com o pedido de autorização para funcionamento da Faculdade de Ciências, Letras e Educação de Presidente Prudente (Faclepp) junto ao Conselho Federal de Educação. Em agosto corrente, esta foi autorizada pelo Conselho e, no dia 3 de outubro de 1972, o presidente da República Emílio Garrastazu Médici assinou o Decreto 71.190 , criando a primeira faculdade da Apec, a Faclepp. Foi então realizado o primeiro Vestibular da Apec, com 536 candidatos concorrentes às 350 vagas oferecidas.

Em 21 de outubro de 1972, o Bispo Diocesano Dom José Gonçalves da Costa proferia a Aula Inaugural da Faclepp (provisoriamente nas dependências do Colégio Cristo Rei).

Em decorrência dos ideais de Agripino e Ana Lima e da grande demanda por outras áreas do conhecimento, nos anos seguintes nasceram as Faculdades da Saúde: Odontologia, Farmácia e Bioquímica, Enfermagem e Obstetrícia, Fisioterapia e suas referidas clínicas, ginásio de esportes e laboratórios. Depois a Faculdade de Engenharia Civil, de Informática e tantos outros cursos superiores. Nos altos do Jardim Bongiovani (Cidade Universitária) surgia velozmente o complexo de prédios que hoje integra o campus I da Unoeste.

Um dado relevante: desde o início, a direção da Apec sempre contou com profissionais competentes. Muitos, até os dias atuais, integram o quadro docente/administrativo da Unoeste.

Pautada pela qualidade de ensino e de vida, a Apec agigantou-se. Em 1987 nascia o Campus II, no Km 572 da Rodovia Raposo Tavares, com cursos nas áreas das Ciências Agrárias, Jurídicas, Administrativas, Contábeis, de Comunicação, entre outras áreas. A clientela acadêmica, bem como a estrutura material, tecnológica e humana multiplicava-se sempre com alto grau de qualidade. Despontavam novos pavilhões, novas clínicas, hospitais, fazenda experimental, prédios laboratoriais, centros agronômico, zootécnico, enfim, áreas destinadas ao ensino superior, à pesquisa científica e à prática constante da cidadania em todas as áreas.

Hoje, desenvolve suas atividades acadêmicas numa área de 5.295.363 m2, incluindo os Campus I, II e III e a Fazenda Experimental.

Outro serviço que tem tido uma participação significativa da Unoeste é o Programa Saúde da Família (PSF), que leva atendimento à periferia, onde reside a população carente. Com a Secretaria Estadual de Saúde, a universidade promove mensalmente cursos de atualização para médicos e também mantém programas de extensão em várias cidades da região.

Em entrevista presencial realizada com o professor Agripino de Oliveira Lima Filho, foram colhidos dados muito importantes a respeito de seu comportamento desde a intenção da fundação da universidade.

$\mathrm{Na}$ década de 70, Agripino percebia que muitas pessoas seguiam para a cidade de Tupã SP para cursar uma faculdade. Observava aquela cena e não aceitava, pois Presidente Prudente é muito maior que Tupã sendo inaceitável que as pessoas saíssem de Presidente Prudente para cursar uma faculdade em outra cidade.

Foi quando Agripino, com o sonho de transformação do cenário educacional prudentino, iniciou em 1972 a realização do projeto de uma faculdade, desejo latente de professores e da população.

Naquela época, não era fácil abrir uma faculdade, implantou a Associação Prudentina de Educação e Cultura (APEC), que seria apenas o início de uma longa caminhada, até o que hoje é a Universidade do Oeste Paulista (UNOESTE).

De faculdade à universidade, a Unoeste 
foi reconhecida pela Portaria Ministerial № 83, em 12 de fevereiro de 1987.

Começou-se com poucos cursos, sendo que um dos primeiros foi o de pedagogia e com 0 passar do tempo cresceu cada vez mais e atualmente a Unoeste oferece 46 cursos de graduação e mais de 60 de pós de graduação (presencias e a distancia).

Entende que não adianta só crescer em número de cursos, mas deve-se crescer na infraestrutura também. Atualmente seus campus universitários possuem uma grande e moderna instalação, oferecendo 0 melhor para seus alunos. A universidade conta com aproximadamente $12 \mathrm{mil}$ alunos $\mathrm{e}$ aproximadamente 2.000 funcionários, assim oferecendo um serviço de qualidade.

Aceitou correr riscos estando sempre preparado para lidar com as situações que ocorriam ao longo de seu caminho, sempre colocando metas a serem atingidas e com muito esforço e dedicação as atingiu sem o uso da ambição.

Sempre foi autoconfiante, não se aventurava, mas sim, sempre foi muito objetivo e direto pensando em seu próprio futuro e no de seus próximos, sendo o que the dava força e confiança até transformar seu sonho em realidade.

É auto motivado até hoje, teve a idéia de criar a faculdade acreditando em seu projeto e o colocando em prática, que se tornou realidade e passou de faculdade para universidade.

Possui uma grande capacidade de trabalho em equipe, toda sua vida foi formada em equipes, tratando os funcionários como membros de sua família. Pensa que não só pagando bem que se forma um bom funcionário, mas também do bom tratamento lhes oferecendo atenção e confiança.

Pelo fato de ter sido professor e diretor de escola adquiriu conhecimentos técnicos, conhecia dificuldades que um profissional poderia enfrentar e com isso, sempre procurou o melhor para seus funcionários exigindo um alto padrão de qualidade para seus alunos. Sabe que um empresário precisa conhecer a sua atividade muito bem e estar sempre atento a tudo o que acontece.

A criatividade sempre foi um diferencial em sua vida, pois sempre a utilizou sendo contrário aos empresários que copiam ideias. Aproveitou a necessidade das pessoas em possuir uma universidade, em especial na cidade de Presidente Prudente instalando assim, a primeira universidade particular da cidade e que Ihe causou uma incrível satisfação em concretizar este sonho.

Suas decisões foram tomadas de forma transparente e sem prejudicar ninguém, tornadose reconhecidos no mercado educacional, o qual, não é fácil ganhar credibilidade e ainda se manter por todos esses anos, tudo isso é fruto de uma decisão bem tomada com responsabilidade.

A determinação se fez presente em suas conquistas, pois para Agripino, o que adiantava ter uma faculdade só com meia dúzia de cursos, gostaria de suprir as necessidades das pessoas que os procuravam, foi então que determinou e lutou para conquistar novos cursos, sempre pensando positivo e acreditando em seu projeto conseguindo transformar uma faculdade em universidade.

Conseguiu oferecer eficiência através dos conhecimentos que adquiria e com visão ampla do negócio sempre buscava oferecer algo a mais e melhor.

Continuamente foi aberto a todos, e procurando saber o que estava se passando e muito objetivo, nunca se abateu, mas sempre se utilizou de uma energia que não o deixava chegar ao desespero, pois possuía confiança em si e em sua equipe.

É flexível até os dias de hoje, estando 
atento com as mudanças, com os concorrentes e com surgimentos de novos cursos para aplicar algo novo dentro da universidade. É necessário agir corretamente, com todos seus cursos reconhecidos pelo MEC e tomando muito cuidado com a qualidade para sempre obter boas notas nas avaliações de seus cursos.

Considera que a iniciativa vem da pessoa, sempre teve capacidade de agir por si mesmo sem medo de na época ser um simples professor, mas que com muito esforço hoje se tornou um vencedor.

Não dependia só de sua pessoa para vencer, mas também da sua equipe, pois do que adiantava ter o projeto se não tivesse uma equipe preparada para agir no momento certo.

Sempre foi otimista, acreditava em si, nunca abaixando sua cabeça com problemas que surgiam porque acreditava em seu sonho, pois não seria somente ele que iria se beneficiar de seu projeto, mas também as pessoas que buscavam uma vida melhor e um novo conhecimento, portanto, sentia que possuía um dever para cumprir e nunca desistiu.

É até hoje muito persistente, sempre buscando o melhor, sem prejudicar a ninguém e pelo contrário, quando via as coisas dando certo pensava mais alto ainda e nunca pensou em desistir frente às dificuldades.

Não sentiu medo porque estava preparado e não se aventurando, percebendo que a cidade de Presidente Prudente e a sua região necessitavam de uma Universidade sólida e transparente, foi onde junto com sua equipe conquistaram essa vitória com muito sucesso que permanece até hoje.

\section{6- CONSIDERAÇÕES FINAIS}

O surgimento da Universidade do Oeste Paulista (Unoeste), embasado nas questões realizadas ao professor Agripino de Oliveira Lima Filho vieram de encontro ao perfil do empreendedor na prática.
A pesquisa sobre o perfil do empreendedor teve uma relevância muito grande por trazer esclarecimentos fundamentados e ainda exemplo do empreendedor no ambiente real. E a definição de Rausp (apud ARAUJO, 2010, p.6): define o nosso entrevistado como empreendedor que é.

Os empreendedores não são apenas aqueles que têm idéias, criam novos produtos ou processos. São os que programam, lideram equipes e vendem suas idéias. É difícil encontrar todas essas características em uma única pessoa, por isso, a identificação do perfil de cada uma é fundamental e o trabalho em equipe é fator essencial para 0 possível sucesso dos empreendedores dentro de uma organização.

\section{REFERÊNCIAS}

Agripino Lima Filho: Um homem de valor. Presidente Prudente. Disponível em:http://www.unoeste.br/fipp/infoeste/21info/ webfif/r9web/unoeste.html\#campus1

ARAUJO, Elisangela, Artigo: Empreendedorismo e características comportamentais dos empreendedores, FAAL - Faculdade de Administração e Artes de Limeira, 2010.

BARBOSA, Áurea; ANDRADE, Liana. Artigo: O empreendedor brasileiro. Faculdade 7 de Setembro, 2002.

BRITTO, Francisco; WEVER, Luiz. Empreendedores brasileiros: vivendo e aprendendo com grandes nomes. Rio de Janeiro: Campus, 2003.

DORNELAS, José Carlos Assis. Empreendedorismo: transformando idéias em negócios. Rio de Janeiro: Elsevier, 2001

MACHADO, Hilka. Causas de mortalidade de pequenas empresas: Coletânea de estudos. 22 ed. Maringá-PR: Eduem, 2007.

PEREIRA, Heitor; Santos, SILVIO. Criando seu próprio negócio: Como desenvolver o potencial empreendedor. $1^{\circ}$ tiragem, Brasília: editora SEBRAE, 1995.

Portal Unoeste. Universidade do Oeste Paulista - Unoeste. Presidente Prudente. Disponível em:http://unoeste.br/site/auniversidade/AUnoeste 
Hoje.aspx. Acesso em 23 abr. 2010.

WIKIPÉDIA. Enciclopédia eletrônica. Disponível em http://pt.wikipedia.org. Acesso em 20 de abril de 2010. 